\title{
THERAPEUTIC MANAGEMENT OF PATIENTS INFECTED WITH SARS-CoV-2 VIRUS - A REVIEW

\author{
Nicoleta Blebea ${ }^{1}$, Gabriela Mitea $^{2}$
}

\begin{abstract}
INTRODUCTION: Due to the rapid outbreak of the pandemic that causes SARS-CoV-2 infection and the increased rate of morbidity and mortality as a result of this new infection, the treatments pursued in therapy must have an increased potential to inhibit the replication of this virus.

OBJECTIVES: The main objective of this article was to describe the most current drug therapies and their mechanisms of action used in the treatment of COVID-19. In this article, we have collected the latest information and multilingual international scientific discoveries about the treatment of COVID-19.

RESULTS: Several compounds can be used to treat COVID-19 in order to reduce the duration of the disease and the rate of infection, to reduce the viral load, to prevent tissue damage, to stimulate the maturation of many cells, including immune cells in the human body and to reduce its severe symptoms. The most effective treatments were based on the antiviral drugs, antimalarial drugs, anti-inflammatory drugs, analgesics drugs, glycopeptide antibiotics, anticoagulants, vitamin $\mathrm{C}$ and vitamin D. The simplest and most direct approach to controlling SARS-CoV-2 outbreaks is the use of passive antibodies transferred from plasma to convalescent patients. Recently, studies have been completed for several vaccines that are approved against SARS-CoV-2.

CONCLUSION: Scientists around the world are collaborating and innovating to make tests, treatments and vaccines available to the public that will save lives collectively and end this pandemic.
\end{abstract}

UDC Classification: 616.9, DOI: https://doi.org/10.12955/pmp.v2.163

Keywords: COVID-19, SARS-CoV-2, pandemic, treatment, vaccine.

\section{Introduction}

SARS-CoV-2 is an encapsulated single-stranded RNA coronavirus belonging to the Coronaviridae family. Coronaviruses infect birds and mammals, causing a range of symptoms, from respiratory diseases to gastrointestinal diseases. Some relatively common seasonal coronaviruses infect humans, causing mild respiratory conditions such as the common cold (Flanagan et al., 2020). Prior to the current pandemic, two high-lethal epidemics caused by human coronaviruses were reported - namely severe acute respiratory syndrome (SARS), caused by SARS-CoV-1, in 2002, with a mortality of about 9\%) and respiratory syndrome in the Middle East (MERS, caused by MERS-CoV, in 2012, with a higher mortality of about 40\%) (Flanagan et al., 2020). On 12 March 2021, more than 118.5 million cases of SARS-CoV-2 infections were reported worldwide, of which more than 2.6 million resulted in deaths. The number of deaths continues to fall in the last six weeks, with a weekly decrease of $6 \%$ compared to the previous week. Several drugs have been approved for temporary use until serious studies prove their efficacy. Meanwhile, a series of clinical trials are underway, the most important being organized by the World Health Organization (WHO) and the National Health Service in the United Kingdom (Marineci et al., 2021).

The paper was based on the most popular methods of identification using words like "COVID-19", "SARS-CoV-2", "pandemic" for the latest international information about the treatment of COVID-19 (by electronic search using Pubmed, SciFinder, Scirus, GoogleScholar and Web of Science). We also consulted the global literature cited in the COVID-19 database of the World Health Organization (WHO) updated daily from the current literature on this topic.

The goal of this article is to highlight the therapeutic measures currently used to treat the symptoms specific to the SARS-CoV-2 virus, based on both the treatments currently used and those with potential authorization in the future. Emphasis is also placed on the mechanisms of immunogenic action of vaccines and the platforms that have enabled their development.

\section{Antiviral drugs}

Camostat mesylate is an antiviral agent that inhibits the activity of several transmembrane serine proteases that SARS-CoV-2 uses to fuse cell membranes between virus and host, such as TMPRSS2, TMPRSS13, TMPRSS11D, $-11 \mathrm{E}$ and 11F. These proteases may be the direct target of this substance in the fight against SARS-CoV-2 infection. By blocking the fusion of membranes, the viral infection can

\footnotetext{
${ }^{1}$ Ovidius University of Constanta, Faculty of Pharmacy, Constanta, Romania, nicoleta.blebea@ gmail.com

${ }^{2}$ Ovidius University of Constanta, Faculty of Pharmacy, Constanta, Romania, gegiugabriela@yahoo.com
} 
be reduced by two thirds, which can lead to a decrease in the infection rate, as well as morbidity and mortality. A preclinical study performed in mice showed a $60 \%$ reduction in lethality due to SARSCoV-2 virus infection with the administration of a $30 \mathrm{mg}$ per kilogram body weight of mesylate camostat twice daily. The effectiveness of this substance was studied in-vitro on human lung cells and the results revealed a significant reduction in the penetration of the virus through the "spike" proteins from its surface (Breining et al., 2021). Camostat mesylate has been tested in various groups of patients with COVID-19 to adequately cover their demographic diversity. Regardless of its antiviral activity, it may reduce the uncontrolled release of cytokines seen in severe COVID-19 cases. An advantage of using camostat mesylate is that it is not metabolized by any CYP system inhibitor. It has a very low potential for pharmacokinetic interaction with other drugs and has a very high safety profile. Therefore, it can be used in combination with Remdesivir and corticosteroids to reduce the penetration and replication of the virus in cells, but also inflammation (Breining et al., 2021).

Umifenovir, an indole derivative known for its antiviral potential in the treatment of several viral infections, may play a role in blocking virus penetration into target cells, inhibiting viral RNA synthesis, and inducing beneficial serum interferon to stimulate immunity. Superior effects of inhibiting viral replication in-vitro for early-stage SARS have been reported. Following a comparative study between two groups of 15 patients each infected with the SARS-CoV-2 virus and hospitalized without comorbidities who received treatment with umifenovir or an antiviral control drug, respectively, the results showed beneficial effects of using umifenovir. No adverse effects were reported after treatment with umifenovir, the time required to suppress the cough was reduced, the symptoms were not aggravated during hospitalization, and after discharge, following monitoring, all patients recovered. However, in other studies, the efficacy of umifenovir for the treatment of COVID-19 in-vivo was not satisfactory (Huang et al., 2021, Yethindra et al., 2020).

In one study, 199 patients confirmed with SARS-CoV-2 infection, with 94\% oxygen saturation, $\mathrm{PaO} 2$ $<300 \mathrm{mmHg}$, hospitalized and mechanically ventilated, were randomized to receive lopinavir/ritonavir treatment. For 14 days, the first batch of 99 patients received lopinavir400mg/ritonavir100mg along with standard antiviral therapy and the second batch of 100 patients received only standard antiviral therapy. The results showed a decrease in the mortality rate for the 99 patients (19.2\% compared to $25 \%$ ), but the time required for clinical improvement was no different between the two groups (Cao et al., 2020).

The only drug fully approved for COVID-19 treatment in October 2020 in adult patients over 12 years of age and those weighing at least $40 \mathrm{~kg}$ is the remdesivir antiviral agent (Cascella et al., 2021). In January 2020 clinical trials that tested remdesivir for the treatment of the first case of COVID-19 in the U.S. obtained positive results in reducing infection-specific phenomena (Holshue et al., 2020). The patient responded rapidly to remdesivir. The rapid and effective improvement of this patient's condition can be attributed to a strong immune system or other supportive treatments (Ghanbari et al., 2020). Based on in vitro studies following administration with chloroquine or hydroxychloroquine, the antagonistic effect on intracellular metabolic activation and antiviral activity of remdesivir has been identified (Cascella et al., 2021).

Favipiravir, another oral antiviral, a selective RNA polymerase inhibitor, is approved in Russia for the treatment of COVID-19. A randomized, $2 / 3$ phase favipiravir clinical trial was performed compared to standard treatment of patients with moderate COVID-19. Viral clearance on day 5 was $62.5 \%$ in favipiravir-treated patients compared to $30 \%$ in patients with standard care. On day 10, viral clearance of $92.5 \%$ was achieved in patients taking favipiravir compared with $80 \%$ in the group of patients receiving standard care (Ivashchenko et al., 2020). On November 9, 2020, the Food and Drug Administration (FDA) issued an emergency authorization to use a monoclonal antibodies that act against the SARS-CoV-2 spike protein called bamlanivimab. It is recommended for use in pediatric patients, those over 12 years of age, weighing at least $40 \mathrm{~kg}$ and adults for the treatment of mild and moderate forms of COVID-19, but also for those at high risk of progression to severe forms and/or hospitalization. An approval for bamlanivimab plus etesevimab was issued on February 9, 2021 (Cascella et al., 2021). Lopinavir and ritonavir, antiviral drugs in the class of protease inhibitors, are commonly associated in antiviral experiments. This combination, known as Kaletra ${ }^{\circledR}$, may act as an inhibitor of viral replication and may increase the half-life and therapeutic effect of lopinavir (Ghanbari et al., 2020). Although evidence suggests that this antiviral drug would have beneficial effects in SARS-CoV-2 infection, a 
randomized study in a group of 199 hospitalized patients diagnosed with severe COVID-19 did not show any beneficial effects. Therefore, its efficacy in the treatment of patients with COVID-19, either as a monotherapy or in combination with other drugs has not yet been well established (Ghanbari et al., 2020).

In an in vitro study based on treatment with nelfinavir, an antiretroviral medicine, the potential to inhibit SARS-CoV replication and reduce the cytopathic effect induced by infection with this virus has been reported. In several SARS-CoV-2 cell culture models, nelfinavir demonstrated the potential to inhibit SARS-CoV-2 replication. Based on its high potency, nelfinavir may benefit from further exploration as a potential inhibitor of SARS-CoV-2 infection in patients with COVID-19 (Ghanbari et al., 2020). In a small clinical study in 11 patients with COVID-19, the therapeutic efficacy of danoprevir, a hepatitis C virus serine protease inhibitor NS3, in combination with ritonavir was demonstrated. This type of combination treatment, administered over a period of 4 to 12 days, was safe and well tolerated by all patients (Ghanbari et al., 2020).

The effectiveness of ribavirin, a guanosine analogue with the ability to block viral RNA synthesis, approved for the treatment of hepatitis $\mathrm{C}$ virus and respiratory syncytial virus, has been evaluated in patients infected with SARS-CoV and MERS-CoV. In an in vitro comparative study evaluating potential antiviral drugs against SARS-CoV-2, the antiviral effects of ribavirin were 100 times less effective than the effects of remdesivir. Both the efficacy and safety of ribavirin and its toxicity in patients with COVID-19 require additional clinical trials.

Galidesivir, an adenosine analogue, may also act as a nucleoside RNA polymerase inhibitor (Ghanbari et al., 2020). This drug can limit the process of viral replication by prematurely stopping RNA transcription. Its antiviral activity against SARS-CoV, MER-CoV and Ebola has been demonstrated. It can be considered as a potential drug in the treatment of SARS-CoV-2 virus in patients with COVID19 with severe symptoms (Ghanbari et al., 2020).

\section{Non-steroidal anti-inflammatory drugs (AINS)}

To demonstrate the efficacy and safety of the use of non-steroidal anti-inflammatory drugs in the treatment protocol of patients with COVID-19, several studies have been performed based on associated treatments. A comparative study was performed between two groups of patients with mild to moderate forms of COVID-19 who received indomethacin and paracetamol, along with standard medication (remdesivir). Patients were monitored clinically and paraclinically daily. It was observed that patients treated with indomethacin showed a remarkable symptomatic improvement compared to those treated with paracetamol. Only one of the patients in the indomethacin group needed extra oxygen, while 28 of the patients in the paracetamol group needed extra oxygen. The first group showed a reduction in the number of days to reduce fever, cough and myalgia, compared to the second group. There is no evidence of an adverse reaction to indomethacin or impaired renal or hepatic function. Due to the faster improvement of symptoms and the progression of pneumonia in patients with COVID-19, standard antiviral therapy combined with indomethacin could replace that associated with paracetamol when there is no contraindication to its use (Ravichandran et al., 2020).

\section{Inhibitors of Janus kinases}

Baricitinib and ruxolitinib are Janus kinases (JAK) belonging to a specific family of TK (tyrosine kinase) which includes four members: JAK1 (Janus-associated kinase 1), JAK2 (Janus-associated kinase 2), JAK3 (Janus-associated kinase 3) and TYK2 (Tyrozine kinase 2). JAKs are related to the intracellular domains of type I/II cytokine receptors. The receptors for this type of cytokine do not show enzymatic activity but depend on how JAK transduces intracellular signals. STAT (signal transducer and transcription activator), a class of transcription factors with cytosolic localization, is an important substrate of JAK. JAK activation leads to phosphorylation of tyrosines in receptor endodomains and various other substrates, the main target protein being STAT. After phosphorylation, STAT dissociates from the receptor and dimerizes. The dimer-shaped STAT translocate into the nucleus, attaches to DNA, and regulates gene expression. It can both activate and suppress genetic transcription. JAK-STAT mediates the effect of many different molecules, including interleukins (IL), interferons (IFN), colonystimulating factors, growth factors, and hormones, which function through type I and II receptors. Inhibitors of Janus kinases interrupts the JAK-STAT pathway. Because many of the key cytokines use this pathway to exert their effects, blocking them with JAK inhibitors offers numerous therapeutic 
possibilities. Immunosuppression induced by this class of drugs could reduce the inflammation and associated immunopathologies identified in patients with COVID-19 (Stebbing et al., 2020, Fragoulis et al., 2019).

Baricitinib is an orally administered selective Janus kinase 1 and 2 inhibitor that inhibits the intracellular signaling pathway of cytokines such as IL-2, IL-6, IL-10 and interferon- $\gamma$. A randomized multinational study was performed that included 1,033 patients (515 received baricitinib plus remdesivir and 518 received control treatment [remdesivir plus placebo]). The result demonstrated antiviral effects by blocking severe acute respiratory syndrome and reduced inflammation in patients with SARS-CoV-2. The results showed that patients receiving baricitinib had a recovery period of 7 days compared to those receiving control treatment ( 8 days), mortality over 28 days was $5.1 \%$ in the combined group and $7.8 \%$ in the control group and the incidence of serious adverse reactions was less frequent in the combined group than in the control group (Richardson et al., 2020, Kalil et al., 2021). Ruxolitinib is a selective JAK oral inhibitor for JAK1 and JAK2, which showed antiviral effects by blocking SARS-CoV-2 in a study in a group of patients treated with ruxolitinib compared to one treated with placebo. Radiographic improvements were detected on computed tomography of the chest on day 14 (90\% for ruxolitinib vs. $61.9 \%$ for placebo) and a shorter time to recovery after initial lymphopenia ( 5 days for ruxolitinib vs. 8 days for placebo) (Cao et al., 2019).

Tocilizumab (TCZ) is an anti-IL-6 monoclonal antibody that inhibits signal transduction, with a significant effect on inhibition of infection-induced cytokines. TCZ has been studied in several clinical studies to evaluate its safety and efficacy with standard therapy in adults hospitalized with COVID-19 compared with placebo treatment with standard therapy. High blood pressure and diabetes were the most common comorbidities, and were similar between the two groups. Early use of TCZ in COVID-19 infection has been beneficial in increasing survival rate, reducing hospital stay, and oxygen demand (Keske et al., 2020).

\section{Glycopeptide antibiotics}

The premise of the possible therapeutic efficacy of glycopeptide antibiotics against SARS-CoV-2 arose as a result of beneficial results in the treatment or prevention of viral infections caused by Coronaviridae, in particular SARS-CoV-2 and MERS-CoV, results obtained by using vancomycin, teicoplanin, rist eremimycin-like aglycones and their semisynthetic derivatives (dalbavancin, oritavancin and telavancin) in vitro and in experimental animals. Teicoplanin was recommended as a potential antiviral and antibacterial agent in a study of 21 patients with severe COVID-19. Patients received $6 \mathrm{mg} / \mathrm{kg}$ teicoplanin every 24 hours (loading dose every 12 hours for three doses) for 7-12 days. The result suggested that the drug has anti-SARS-CoV-2 activity with a reduced risk of nephrotoxicity and rash (Demsie et al., 2020). The first results obtained from the beginning of the pandemic with over 100 patients showed the apparent efficiency of chloroquine in reducing the exacerbation of pneumonia, the duration of the symptoms and viral clearance, as well as the absence of severe side effects.

\section{Antimalarial drugs}

Chloroquine was included in the recommendations for the prevention and treatment of pneumonia in COVID-19 (Gao et al., 2020). Chloroquine is an antiviral known for blocking the virus penetration into the cells by increasing the endosomal $\mathrm{pH}$, as well as for the inhibition of glycosylation of the cellular receptors of SARS-CoV (Vincent et al., 2005).

Hydroxychloroquine, in comparison with chloroquine, inhibits SARS-CoV-2 for 7.6 times more efficiently in vitro (Yao et al., 2020). The two medicines may inhibit the reapplication of the nucleic acid, glycosylation of the viral proteins, assembling the virus and releasing the virus from the infected cell (Rolain et al., 2007). In 2020, 21 clinical studies were initiated by hospitals in China and by Oxford University for the evaluation of the efficiency of these agents in the infection with SARS-CoV-2 (Mitea et.al., 2020). At the beginning of the summer of 2020, the Recovery British study did not find a benefit in the use of hydroxychloroquine, and the World Health Organization stopped the studies for hydroxychloroquine. Additionally, within the Solidarity study in which 954 patients received hydroxychloroquine, a decrease of mortality or a modification of the evolution of the disease was not noticed. In July 2020, another American study showed a decrease of mortality in cases where both hydroxychloroquine and azithromycin were used. It was noticed that the patients treated with hydroxychloroquine combined with the antibiotic macrolide azithromycin were cured $100 \%$ compared 
to patients treated only with hydroxychloroquine (57.1\%) and those from the control group (12.5\%), although later the results of this study were questioned. At this point there is a large number of patients enrolled in studies with chloroquine, hydroxychloroquine and different combinations of medicines that include them (Gautret et al., 2020).

\section{COVID-19 vaccines}

The vaccines that prevent infection with SARS-CoV-2 and/or the disease caused by it, COVID-19, are considered the most promising approach for stopping the pandemic. Worldwide, the number of doses of vaccine administrated exceed 2-3 times the number of infections from the beginning of March 2021, and the percentage increases vertiginously day by day (Marineci et al., 2021). The vaccines against COVID-19 mainly use as antigenic target, the spike protein. Similar to classic vaccines, vaccines that contain either live attenuated virus, inactivated virus, or protein fragments are developed. Another strategy to induce immunity against SARS-CoV-2 is the use of genetic material, DNA or messenger RNA, which orders in the body of the vaccinated patient a ribosomal synthesis of spike proteins, towards which the immunity system of the vaccinated patient develops an immune response. The $\mathrm{S}$ (spike) protein is the immunodominant antigen of SARS-CoV-2 virus and the neutralizing antibodies attach and block the binding domain of the receptors of the S1 subunit of this protein. Thus, they prevented the binding of the virus to the ACE2 receptor and consequently the penetration of the virus into the cell. Most anti-COVID-19 vaccines determine the expression in the body of the vaccinated patient of the $S$ protein, which triggers the protective immune response. This then results in the body producing neutralizing antibodies and the generation of immunity mediated by T lymphocytes (Creech et al., 2021).

\section{Convalescent plasma}

Convalescent plasma was administrated in the treatment of COVID-19 immediately after the start of symptoms, and the probability of mortality after the treatment was reduced in comparison with the placebo (Mitea et.al., 2020). If during the infection patients were treated with convalescent plasma or with monoclonal antibodies, vaccination against COVID-19 was held off for a minimum of 90 days after treatment (Marineci et al., 2021).

\section{Analgesics drugs}

Within the context of the COVID-19 pandemic, paracetamol is recommended by all the international organizations for the symptomatic treatment of the disease, as it follows: the European Medicine Agency (EMA) recommended paracetamol for the treatment of pain and fever caused by the infection with SARS-Cov-2. The WHO includes at present paracetamol as a first line treatment for the palliative care of patients with COVID-19 (Mitea et.al., 2020).

\section{Anticoagulant drugs}

The discovery that COVID-19 can cause blood clots in patients with severe forms of the disease has led doctors to prescribe anticoagulant therapy. Not all the asymptomatic patients diagnosed with COVID19 should take this type of therapy, only those receiving chronic anticoagulant therapy. This therapy should also be followed by patients at high risk of thromboembolism, caused by other chronic diseases. All the symptomatic patients diagnosed with COVID-19 should be treated with anticoagulants. The therapeutical regime (prophylactic or curative) shall be individually selected, based on the class of thromboembolic risk, and the hemorrhagic risk. The treatment with anticoagulants for curative purposes are indicated in the case of patients with high thromboembolic risk and low bleeding risk. The American Society of Hematology and the International Society of Hemostasis and Thrombosis recommend the administration of low molecular weight heparin in prophylactic doses (HGMM) for all the patients hospitalized for COVID-19, if there are no major counter indications (active bleeding). The equivalent dose of administration (subcutaneous) of the low molecular weight heparin for the thromboprophylaxis of the patients with small or intermediary risk (at the decision of the attending physician): enoxaparin for the patients with creatinine clearance $(\mathrm{ClCr})>30 \mathrm{~mL} / \mathrm{min}$, a single dose of $40 \mathrm{mg} /$ day; for $\mathrm{ClCr}$ between 15 and $30 \mathrm{~mL} / \mathrm{min}$ a single dose of $30 \mathrm{mg} /$ day; dalteparin a dose of 5000 units/day; dadroparin for patients with weight $\leq 70 \mathrm{~kg}$, a single dose of 3800 or 4000 units anti-factor Xa/day for patients with weight $>70 \mathrm{~kg}$, a single dose of 5700 units/day; tinzaparin a single dose of 4500 units anti-factor Xa/day. It is recommended of the doses of low molecular weight heparin be adjusted based on the clinical situation (an associated disease such as a renal disease or obesity). For the patients with $\mathrm{ClCr}<15$ $\mathrm{mL} / \mathrm{min}$ or enrolled in the dialyze program, unfractionated heparin is recommended. For patients with 
anticoagulant contraindication is recommended mechanical thromboprophylaxis. Oral anticoagulants (especially DOAC direct oral anticoagulants) are not recommended, due to some possible interactions with other medicines administrated to patients with COVID-19. Their presence in the current treatment of patients with COVID-19 requires the switch to parenteral anticoagulants in the curative dose (HGMM or HNF) (Mitea et.al.,2020). Studies from Netherlands and France suggest that clots occur in 20-30\% of critically ill patients diagnosed with COVID-19 (Klok et al., 2020). Many hospitalized patients have increased levels of a protein fragment called D-dimers, which is generated when a clot is dissolved. The high levels of D-dimers maybe is a strong predictor of mortality of the infected hospitalized patients (Zhang et al., 2020).

\section{Vitamins}

Vitamin D influences the expression of different genes involved in the immunity system and the inflammatory cascade. Supplementing with vitamin D is useful in COVID-19 infection as a preventive and therapeutic agent. A deficit of vitamin D is strongly corelated with the risk of infection in observational studies. Old people have a weaker immunity system and associated comorbidities and are more vulnerable to immune response dysfunction, as most of them have concomitantly severe deficit of vitamin D. So far, the studies have shown the protective effects of vitamin D3 (cholecalciferol) combined with $\mathrm{Mg}$ and vitamin B12 against the clinical aggravation of patients infected with COVID19. In a metanalysis it is shown that supplementing with vitamin $D$ is both a safe and efficient way for preventing acute infections of the respiratory tract (Martineau et al., 2017). It was observed that the protective role of vitamin D was efficient at patients with initial serum levels of $25(\mathrm{OH}) \mathrm{D}<25 \mathrm{nmol} /$ L comparing to those with serum concentrations of $25(\mathrm{OH}) \mathrm{D}>25 \mathrm{nmol} / \mathrm{L}$. In the same study, the analysis of the subgroups indicated that the daily intake of vitamin $\mathrm{D}$ has protective effects against acute infections of the respiratory tract, especially in persons with a deficit of vitamin D. Supplementing with vitamin $\mathrm{D}$ also indicated an increase in the expression of genes related to antioxidation (glutathione reductase modificatory subunit) (Lei et al., 2017). The increased production of glutathione maintains the use of vitamin C, which has antimicrobial properties (Coluga et al., 2020) and was suggested in the prevention and treatment of the infection with COVID-19 (Grant et al., 2020). Vitamin D supplementation with doses up to 100g/day is safe for adults (Bischoff et al.,2010) and experts now suggest supplementation in the elderly as well. Charoenngam et al. (2020) reported that the intake of vitamin D at 100-250 g/day for 6 weeks increases the initial serum concentration without side effects. Thus, the literature suggests that the administration of up to $250 \mathrm{~g} /$ day of vitamin $\mathrm{D}$ for a month is efficient for increasing the serum level of $25(\mathrm{OH}) \mathrm{D}$ in the optimum interval between 75 and $125 \mathrm{nmol}$ / L, the dose may be reduced to $100 \mathrm{~g} /$ day for maintaining the circulant concentration of $25(\mathrm{OH})$. Having in view the present data and the recommendations recently published, the supplementation of vitamin D to patients with deficit levels should be a priority during the COVID-19 pandemic. Optimum vitamin D levels may be obtained with oral doses between 1800 and 4000 UI of vitamin D per day (Bischoff et al., 2010).

\section{Discussion}

COVID-19 was originally described as a viral pneumonia because it caused acute and possibly fatal respiratory illness. Later, however, other types of non-specific COVID-19 symptoms were described: gastrointestinal, neurological, dermatological and even psychiatric. Therefore, in order to establish a clear diagnosis, it is necessary to perform a real-time polymerase chain reaction (PCR) test to detect the virus on the nasopharyngeal mucosa. The treatment for COVID-19 is not yet specific (there is no specific antiviral treatment), which is symptomatic (antipyretic, anti-inflammatory, antitussive, etc.) and for the prophylaxis of complications (anticoagulant, antibiotic therapy, respiratory support, vitamin therapy).

In patients with severe symptoms and critically ill patients, the use of medication should be evaluated more closely in randomized controlled trials.

In addition to medication, vaccines are the solution to limit the number of infected persons and stop the transmission of the virus.

Due to the exponential growth of infections, many countries have taken rapid and rigorous nonpharmaceutical measures to prevent and control them. Given the predominantly airborne route of transmission (along with that through contaminated hands), it is essential to isolate patients confirmed 
with COVID-19 or suspected of having COVID-10. Non-COVID-19 patients should also be isolated so as to minimize the risk of contamination.

The pandemic caused by the new coronavirus is of great importance for public health, and its evolution is a cause for concern (Mitea et al., 2020).

\section{Conclusion}

To date, the COVID-19 pandemic is the most important public health challenge facing humanity in the third millennium. Its implications extend to the economic, political and social spheres.

In addition to drug treatments and behavioral measures, vaccines are the solution to limit the number of infected persons and stop the pandemic.

The scientific community has mobilized exemplarily and, with the financial and regulatory support of states, in less than a year since the sequencing of the SARS-CoV-2 genome, many vaccines have reached advanced stages of clinical testing, some of which are already authorized to be used in vaccination campaigns.

\section{References}

Bischoff-F., H. A., Shao, A., Dawson-Hughes, B., Hathcock, J., Giovannucci, E., \& Willett, W. C. (2010). Benefit-risk assessment of vitamin D supplementation. Osteoporosis international : a journal established as result of cooperation between the European Foundation for Osteoporosis and the National Osteoporosis Foundation of the USA, 21(7), 11211132. https://doi.org/10.1007/s00198-009-1119-

Breining, P., Frølund, A. L., Højen, J. F., Gunst, J. D., Staerke, N. B., Saedder, E., Cases-Thomas, M., Little, P., Nielsen, L. P., Søgaard, O. S., \& Kjolby, M. (2021). Camostat mesylate against SARS-CoV-2 and COVID-19-Rationale, dosing and safety. Basic \& clinical pharmacology \& toxicology, 128(2), 204-212. https://doi.org/10.1111/bcpt.13533

Cao, Y., Wei, J., Zou, L., Jiang, T., Wang, G., Chen, L., Huang, L., Meng, F., Huang, L., Wang, N., Zhou, X., Luo, H., Mao, Z., Chen, X., Xie, J., Liu, J., Cheng, H., Zhao, J., Huang, G., Wang, W., ... Zhou, J. (2020). Ruxolitinib in treatment of severe coronavirus disease 2019 (COVID-19): A multicenter, single-blind, randomized controlled trial. The Journal of allergy and clinical immunology, 146(1), 137-146.e3. https://doi.org/10.1016/j.jaci.2020.05.019

Cao, B., Wang, Y., Wen, D., Liu, W., Wang, J., Fan, G., Ruan, L., Song, B., Cai, Y., Wei, M., Li, X., Xia, J., Chen, N., Xiang, J., Yu, T., Bai, T., Xie, X., Zhang, L., Li, C., Yuan, Y., ... Wang, C. (2020). A Trial of Lopinavir-Ritonavir in Adults Hospitalized with Severe Covid-19. The New England journal of medicine, 382(19), 1787-1799.

https://doi.org/10.1056/NEJMoa2001282

Cascella, M., Rajnik, M., Cuomo, A., Dulebohn, S. C., \& Di Napoli, R. (2021). Features, Evaluation, and Treatment of Coronavirus (COVID-19). In StatPearls. StatPearls Publishing.

Charoenngam, N., Shirvani, A., Kalajian, T. A., Song, A., \& Holick, M. F. (2020). The Effect of Various Doses of Oral Vitamin $\mathrm{D}_{3}$ Supplementation on Gut Microbiota in Healthy Adults: A Randomized, Double-blinded, Dose-response Study. Anticancer research, 40(1), 551-556. https://doi.org/10.21873/anticanres.13984

Colunga B., R., Berrill, M., \& Marik, P. E. (2020). The antiviral properties of vitamin C. Expert review of anti-infective therapy, 18(2), 99-101. https://doi.org/10.1080/14787210.2020.1706483

Creech, C. B., Walker, S. C., \& Samuels, R. J. (2021). SARS-CoV-2 Vaccines. JAMA, 325(13), 1318-1320. https://doi.org/10.1001/jama.2021.3199

Demsie, D. G., Gebre, A. K., Yimer, E. M., Alema, N. M., Araya, E. M., Bantie, A. T., Allene, M. D., Gebremedhin, H., Yehualaw, A., Tafere, C., Tadese, H. T., Amare, B., Weldekidan, E., \& Gebrie, D. (2020). Glycopeptides as Potential Interventions for COVID-19. Biologics : targets \& therapy, 14, 107-114. https://doi.org/10.2147/BTT.S262705

Flanagan, K. L., Best, E., Crawford, N. W., Giles, M., Koirala, A., Macartney, K., Russell, F., Teh, B. W., \& Wen, S. C. (2020). Progress and Pitfalls in the Quest for Effective SARS-CoV-2 (COVID-19) Vaccines. Frontiers in immunology, 11, 579250. https://doi.org/10.3389/fimmu.2020.579250

Fragoulis, G. E., McInnes, I. B., \& Siebert, S. (2019). JAK-inhibitors. New players in the field of immune-mediated diseases, beyond rheumatoid arthritis. Rheumatology (Oxford, England), 58(Suppl 1), i43-i54. https://doi.org/10.1093/rheumatology/key276

Gao, J., Tian, Z., \& Yang, X. (2020). Breakthrough: Chloroquine phosphate has shown apparent efficacy in treatment of COVID-19 associated pneumonia in clinical studies. Bioscience trends, 14(1), 72-73. https://doi.org/10.5582/bst.2020.01047

Gautret, P., Lagier, J. C., Parola, P., Hoang, V. T., Meddeb, L., Mailhe, M., Doudier, B., Courjon, J., Giordanengo, V., Vieira, V. E., Tissot Dupont, H., Honoré, S., Colson, P., Chabrière, E., La Scola, B., Rolain, J. M., Brouqui, P., \& Raoult, D. (2020). Hydroxychloroquine and azithromycin as a treatment of COVID-19: results of an open-label non-randomized clinical trial. International journal of antimicrobial agents, 56(1), 105949. https://doi.org/10.1016/j.ijantimicag.2020.105949

Ghanbari, R., Teimoori, A., Sadeghi, A., Mohamadkhani, A., Rezasoltani, S., Asadi, E., Jouyban, A., \& Sumner, S. C. J. (2020). Existing antiviral options against SARS-CoV-2 replication in COVID-19 patients. Future Microbiology, 15(18). https://doi.org/10.2217/fmb-2020-0120 
Grant, W. B., Lahore, H., McDonnell, S. L., Baggerly, C. A., French, C. B., Aliano, J. L., \& Bhattoa, H. P. (2020). Evidence that Vitamin D Supplementation Could Reduce Risk of Influenza and COVID-19 Infections and Deaths. Nutrients, 12(4), 988. https://doi.org/10.3390/nu12040988

Holshue, M. L., DeBolt, C., Lindquist, S., Lofy, K. H., Wiesman, J., Bruce, H., Spitters, C., Ericson, K., Wilkerson, S., Tural, A., Diaz, G., Cohn, A., Fox, L., Patel, A., Gerber, S. I., Kim, L., Tong, S., Lu, X., Lindstrom, S., Pallansch, M. A., ... Washington State 2019-nCoV Case Investigation Team (2020). First Case of 2019 Novel Coronavirus in the United States. The New England journal of medicine, 382(10), 929-936. https://doi.org/10.1056/NEJMoa2001191

Huang, D., Yu, H., Wang, T., Yang, H., Yao, R., \& Liang, Z. (2021). Efficacy and safety of umifenovir for coronavirus disease 2019 (COVID-19): A systematic review and meta-analysis. Journal of medical virology, 93(1), 481-490. https://doi.org/10.1002/jmv.26256

Ivashchenko, A. A., Dmitriev, K. A., Vostokova, N. V., Azarova, V. N., Blinow, A. A., Egorova, A. N., Gordeev, I. G., Ilin, A. P., Karapetian, R. N., Kravchenko, D. V., Lomakin, N. V., Merkulova, E. A., Papazova, N. A., Pavlikova, E. P., Savchuk, N. P., Simakina, E. N., Sitdekov, T. A., Smolyarchuk, E. A., Tikhomolova, E. G., Yakubova, E. V., ... Ivachtchenko, A. V. (2020). AVIFAVIR for Treatment of Patients with Moderate COVID-19: Interim Results of a Phase II/III Multicenter Randomized Clinical Trial. Clinical infectious diseases : an official publication of the Infectious Diseases Society of America, ciaa1176. Advance online publication. https://doi.org/10.1093/cid/ciaa1176

Kalil, A. C., Patterson, T. F., Mehta, A. K., Tomashek, K. M., Wolfe, C. R., Ghazaryan, V., Marconi, V. C., Ruiz-Palacios, G. M., Hsieh, L., Kline, S., Tapson, V., Iovine, N. M., Jain, M. K., Sweeney, D. A., El Sahly, H. M., Branche, A. R., Regalado Pineda, J., Lye, D. C., Sandkovsky, U., Luetkemeyer, A. F., ... ACTT-2 Study Group Members (2021). Baricitinib plus Remdesivir for Hospitalized Adults with Covid-19. The New England journal of medicine, 384(9), 795-807. https://doi.org/10.1056/NEJMoa2031994

Keske, Ş., Tekin, S., Sait, B., İrkören, P., Kapmaz, M., Çimen, C., Uğur, S., Çelebi, İ., Bakır, V. O., Palaoğlu, E., Şentürk, E., Çağlayan, B., Çakar, N., Tabak, L., \& Ergönül, Ö. (2020). Appropriate use of tocilizumab in COVID-19 infection. International journal of infectious diseases : IJID : official publication of the International Society for Infectious Diseases, 99 , 338-343. https://doi.org/10.1016/j.ijid.2020.07.036

Klok, F. A., Kruip, M., van der Meer, N., Arbous, M. S., Gommers, D., Kant, K. M., Kaptein, F., van Paassen, J., Stals, M., Huisman, M. V., \& Endeman, H. (2020). Incidence of thrombotic complications in critically ill ICU patients with COVIDThrombosis research, 191, 145-147. https://doi.org/10.1016/j.thromres.2020.04.013

Lei, G. S., Zhang, C., Cheng, B. H., \& Lee, C. H. (2017). Mechanisms of Action of Vitamin D as Supplemental Therapy for Pneumocystis Pneumonia. Antimicrobial agents and chemotherapy, 61(10), e1226-17. https://doi.org/10.1128/AAC.0122617

Marineci C.D., Valeanu A., Negres S., Chirita C. (2021). Vaccination against COVID-19. Farmacist.ro, 198, 7-16. https://doi.org /10.26416/Farm.198.1.2021.4353

Martineau, A. R., Jolliffe, D. A., Hooper, R. L., Greenberg, L., Aloia, J. F., Bergman, P., Dubnov-Raz, G., Esposito, S., Ganmaa, D., Ginde, A. A., Goodall, E. C., Grant, C. C., Griffiths, C. J., Janssens, W., Laaksi, I., Manaseki-Holland, S., Mauger, D., Murdoch, D. R., Neale, R., Rees, J. R., ... Camargo, C. A., Jr (2017). Vitamin D supplementation to prevent acute respiratory tract infections: systematic review and meta-analysis of individual participant data. BMJ (Clinical research ed.), 356, i6583. https://doi.org/10.1136/bmj.i6583

Mitea, G., Bucur, M., Dumitru, I. M., Rugina, S., \& Bucur, L. (2020). Therapeutic options in SARS-CoV-2 infection. Farmacist.ro, 195, 14-19. https://doi.org/10.26416/Farm.195.4.2020.3729

Ravichandran, R., Purna, P., Vijayaragavan, S., Kalavakollu, R. T., Gaidhane, S., \& Kumar, R. K. (2020). Efficacy and Safety of Indomethacin in Covid-19 patients. medRxiv

Richardson, P., Griffin, I., Tucker, C., Smith, D., Oechsle, O., Phelan, A., Rawling, M., Savory, E., \& Stebbing, J. (2020) Baricitinib as potential treatment for 2019-nCoV acute respiratory disease. Lancet (London, England), 395(10223), e30-e31. https://doi.org/10.1016/S0140-6736(20)30304-4

Rolain, J. M., Colson, P., \& Raoult, D. (2007). Recycling of chloroquine and its hydroxyl analogue to face bacterial, fungal and viral infections in the 21 st century. International journal of antimicrobial agents, 30(4), 297-308. https://doi.org/10.1016/j.ijantimicag.2007.05.015

Stebbing, J., Phelan, A., Griffin, I., Tucker, C., Oechsle, O., Smith, D., \& Richardson, P. (2020). COVID-19: combining antiviral and anti-inflammatory treatments. The Lancet. Infectious diseases, 20(4), 400-402. https://doi.org/10.1016/S14733099(20)30132-8

Vincent, M. J., Bergeron, E., Benjannet, S., Erickson, B. R., Rollin, P. E., Ksiazek, T. G., Seidah, N. G., \& Nichol, S. T. (2005). Chloroquine is a potent inhibitor of SARS coronavirus infection and spread. Virology journal, 2, 69. https://doi.org/10.1186/1743-422X-2-69

Yao, X., Ye, F., Zhang, M., Cui, C., Huang, B., Niu, P., Liu, X., Zhao, L., Dong, E., Song, C., Zhan, S., Lu, R., Li, H., Tan, W., \& Liu, D. (2020). In Vitro Antiviral Activity and Projection of Optimized Dosing Design of Hydroxychloroquine for the Treatment of Severe Acute Respiratory Syndrome Coronavirus 2 (SARS-CoV-2). Clinical infectious diseases : an official publication of the Infectious Diseases Society of America, 71(15), 732-739. https://doi.org/10.1093/cid/ciaa237

Yethindra, V., Tagaev, T., Uulu, M., S., \& Parihar, Y. (2020). Efficacy of umifenovir in the treatment of mild and moderate COVID-19 patients. International Journal of Research in Pharmaceutical Sciences, 11(SPL1), 506-509.

https://doi.org/10.26452/ijrps.v11iSPL1.2839

Zhang, L., Yan, X., Fan, Q., Liu, H., Liu, X., Liu, Z., \& Zhang, Z. (2020). D-dimer levels on admission to predict in-hospital mortality in patients with Covid-19. Journal of thrombosis and haemostasis : JTH, 18(6), 1324-1329.

https://doi.org/10.1111/jth.14859 